Anuario del Instituto de Historia Argentina, vol. 17, n 2, e050, diciembre 2017.

ISSN 2314-257X

Universidad Nacional de La Plata.

Facultad de Humanidades y Ciencias de la Educación.

Centro de Historia Argentina y Americana

\title{
La particular clave borbónica del gobierno de Bruno de Zavala
}

\section{The specific bourbon key of Bruno de Zavala government}

\section{Griselda Tarragó}

Centro de Investigaciones de la Facultad de Filosofía y Humanidades (CIFFyH) Universidad Nacional de Córdoba, Argentina | griseldatarrago@hotmail.com

\section{PALABRAS CLAVE}

Reformismo

Borbones

Gobierno temporal

Territorios

Agentes políticos

\section{RESUMEN}

Este artículo se propone explorar el llamado proceso de “reformas borbónicas” en el Río de la Plata en su etapa más temprana de la primera mitad del siglo XVIII, durante la gobernación de Bruno de Zavala. La pregunta que lo guía se refiere al impacto de estas nuevas estrategias sobre el universo político y cultural de la tradicional monarquía compuesta hispánica. La elección de este tema constituye un desafío y también una oportunidad para abordar el problema de la agencia monárquica en tiempos de Felipe V, y pretende instalar una mirada crítica sobre ciertos tópicos acerca del reformismo del periodo.

KEYWORDS

Reformismo

Borbones

Gobierno temporal

Territorios

Agentes políticos

\section{ABSTRACT}

This article intends to explore and the so called process of "Bourbon reforms" in the Rio de la Plata at its earliest stage of the first half of the eighteenth century, during the governorship of Bruno de Zavala. The guiding question concerns the impact of these new strategies on the political and cultural universe of the traditional Hispanic composite monarchy. The election of this theme constitutes a challenge and also an opportunity to address the problem of the monarchist agency in the time of Felipe $\mathrm{V}$ and tries to install a critical look on certain topics about the reformism of the period. 


\section{Introducción}

La Europa del Antiguo Régimen devela unas dinámicas del poder en unas monarquías pluriterritoriales, compuestas, de agregación, de reinos múltiples, conglomerados dinásticos donde el principio agregativo instituía el basamento de la organización social. Casa, ciudad, aldeas, villas, ciudades, provincias, reinos, imperios conformaban sus muchas y diversas partes sin cercenar la dialéctica siempre tensa entre unidad y variedad, integración y conflicto, en el seno de un cuerpo político de dimensiones planetarias. En este sentido, las monarquías compuestas eran algo más que una mera yuxtaposición de reinos bajo un mismo soberano. Significaban una nueva cohesión donde un "rey prudente”, un poco padre y juez (Rosanvallon, 2015, pp. 277-296), también negociaba lealtades.

¿Cómo impactó la llegada de los Borbones en ese mundo hispánico plural? Cierta historiografía fue imponiendo la premisa de que la llegada de la nueva dinastía significó también la trasformación de los fundamentos filosófico-políticos del gobierno. Sin embargo, aun en pleno siglo XVIII se desarrolla una monarquía múltiple, “con variadas experiencias discursivas e históricas, y por ello compuesta de grupos y reinos que no fueron absorbidos o eliminados por el discurso y la disciplina monárquica” (Feros, 1996, p.18)

Tal como afirma el profesor Arrieta

En los estudios actuales sobre la formación de España como nación está muy extendida la tendencia a centrar la atención en el siglo XVIII como punto inicial del proceso, precisamente por la importancia que se concede a los cambios introducidos por la dinastía borbónica. No se trata de minusvalorarlos, pero considero que es excesivo ponerlos en los niveles del cambio cualitativo absoluto, como si hubiera un antes y un después. El propio contenido de los puntos anteriores nos da pie para poner en cuestión seriamente tal perspectiva, a la luz de algunos de los acercamientos más lúcidos, en mi opinión, a esta cuestión. Creo que estamos en condiciones mejores actualmente para valorar lo que representa el siglo XVIII en la trayectoria de la formación de una nación española, si se valora debidamente el grado de cambio real que supuso en relación con los dos siglos precedentes (Arrieta, 2009, p. 20).

Cierta tradición difundida buscó “orígenes” o “antecedentes” de los estados emergentes. Respondiendo a las urgencias que planteaba el siglo XIX, se escribieron historias nacionales centralizadoras cuyo objetivo era plantar los cimientos de los nuevos países: "De esta manera, las necesidades de la creación de una imagen nacional han sacrificado en el altar de los mitos republicanos la coherencia de la continuidad histórica...” (Lucena Guiraldo, 1996, p. 266).

En los últimos años se ha puesto sobre la mesa de discusión la categoría historiográfica de reformas borbónicas o la de reformismo borbónico, dada su notable presencia en los estudios desde los años 70 del siglo XX hasta los albores del nuevo milenio (Adrien, 2012). Se ha identificado al siglo XVIII como un sinónimo de reformismo poniendo énfasis en los aspectos casi estrictamente institucionales, económicos, fiscales. En ello también hay una pauta que tiende a identificar casi esencialmente esa categoría con el reinado de Carlos III, obliterando todo el siglo detrás de categorías como la de despotismo ilustrado (Sánchez Blanco, 2002, p. 9; Outram, 2011; RuizTorres, 2008, p. 425). En el mismo sentido, se ha procedido también con operaciones intelectuales que 
desplazaron el mote de reformista a toda acción política o iniciativa gubernamental, en la presunción de la existencia de un "programa” ordenado de ejecución, cuestión que se ve interpelada desde una mirada menos funcionalista (Sánchez Santiró, 2016, p. 45; Pearce, 2014)

La Argentina no escapó a esta tendencia. Para esta historiografía, la creación del Virreinato del Río de la Plata en 1776 plasmó no sólo la apertura oficial y definitiva de este espacio hacia la metrópoli, sino también la introducción del mismo en el programa de reformas borbónico. La obra de Bartolomé Mitre, Ricardo Levene, y otras, como las de Manfred Kossok (1972), quisieron ver en ese corte el momento fundacional del estado moderno argentino, sus “orígenes”, gestado -como “debía” ser- en las entrañas mismas de Buenos Aires y de su puerto atlántico. También la obra de Lynch abunda sobre este enfoque, ya que el autor se centra en la creación del virreinato y la implementación de la Real Ordenanza de Intendentes como la médula del momento (Lynch, 1958)

Estas consideraciones son especialmente contributivas a la hora de explorar el período de tempranas “reformas borbónicas” en el Río de la Plata. Los estudios tradicionales de las grandes colecciones de historia argentina de las décadas de los 40, 50 y 60 del siglo XX (Ravignani, 1938; Levene, 1961) constituyeron un manantial inagotable de información factual densa, contundente y compleja. Información que resulta necesaria, pero no suficiente, especialmente porque en la mayoría de los casos, la misma se encuentra constreñida dentro de los límites de una historia institucional, que se ciñe demasiado a la letra de la normativa oficial (Tarragó, 2013)

Se impone no solo la acción de repensar el período en otras claves (como las de la nueva historia política), sino también desnaturalizar cualquier proyección sobre periodos y espacios que no necesariamente debieron experimentar términos similares. Asimismo, es necesario rescatar de la oscuridad a la primera mitad del XVIII, signada tanto por los avatares de la guerra a escala global como por la falta de recursos, consensos y apoyos suficientes para generar la transformación y el reordenamiento del mundo "austracista". En los últimos años algunos autores han avanzado en esta reconsideración tanto del periodo como del enfoque (Jumar 2000; Trujillo, 2013; Birocco, 2015; Moriconi, 2014).

\section{Los caminos discordantes de la transformación}

Por lo tanto, lejos de las pretensiones centralizadoras de la nueva progenie que tradicionalmente se han venido explicando, esas intenciones no se impondrían por decreto sobre un cosmos político y social esencialmente penetrado -y conformado por una identidad cultural y jurídica de un territorio compuesto y múltiple-, en el que el rey detentaba un poder preeminente antes que absoluto. Era entonces el gran árbitro que, a través del dispositivo de gobierno, mantenía el equilibrio entre los diferentes grupos. Un árbitro, pero también un padre, habilitado para intervenir en cualquier nivel para restablecer la justicia, para devolver a cada uno lo que le correspondía. Cualquier decisión tendía a equilibrar el cuerpo social, siempre y cuando no fuera contra el derecho de gentes ni el derecho natural.

Dotar de recursos a un territorio marginal (como sucedió en otros espacios similares) fue una tarea casi artesanal en la que unos gobernadores “borbónicos” debieron negociar sus medidas con agentes diversos, transitando atajos disímiles que conectaban a la Corte y a las nuevas secretarías del 
Despacho con esos nuevos "políticos”, que intentaban ejecutar las medidas que el primer Borbón proponía para unas tierras mucho más expuestas a expolios diversos luego de Utrecht.

Al fortalecimiento en sí mismo del cargo y figura del gobernador se sumará la necesidad de su calidad de militar calificado y de carrera, requerimiento que se acompasó con la creciente “militarización en la función de gobierno” (Andújar Castillo, 2004). Estas nuevas cualidades se condujeron al menos por dos vías, que también respondían a un proceso de transformaciones más globales. Por una parte, la nueva forma en que la política de los territorios se gestionó en esta etapa fue esencialmente conducida por los secretarios del Despacho de Felipe V, los cuales usaron el “despacho a boca” y la "vía reservada” como una forma expeditiva de ejecutar acciones urgentes; dotaron, a su vez, a los gobernantes de las herramientas necesarias para que la mano de Felipe V pudiera comenzar a diseñar una territorialidad diferente. (Dedieu, 2001; Guerrero Elecalde, 2012). El especial momento y las inseguridades derramadas sobre América obligaron a la Corona a generar cambios de estrategias políticas.

Estas secretarías se caracterizaron por ser instituciones jerárquicas y personalizadas, pero a la vez, con una mayor racionalidad de funciones que se verificó en la progresiva especialización de sus empleados. Respecto a su régimen interno, cada secretaría giraba en torno al titular. En un principio, la no regulación oficial sobre las cualidades y formación de los oficiales ayudó a que los secretarios del Despacho siguieran manteniendo una amplia facultad a la hora de elevar la propuesta de los aspirantes al monarca, controlando firmemente la trama administrativa y potenciando a miembros de su propia familia y allegados. Esta introducción de parientes en la administración real se realizó a partir de la lógica de la casa, lo que provocó que los lazos y vínculos entre el secretario del Despacho y sus oficiales fueran especialmente estrechos, ya que cubrían buena parte de las condiciones exigidas para ocupar estos puestos, como lo eran la confianza y la buena ley, y el hecho de cerrar filas a la hora de enfrentar a facciones contrarias. A estas tendencias se sumó la estrecha relación con el monarca, lo que los constituyó en verdaderos intermediarios con el gobierno por la vía reservada (Lopez Cordon, 1996, p. 124).

La Secretaría del Despacho de Indias y Marina (Pérez Prendes,1989, p. 335) fue concebida como soporte de las decisiones y relaciones regias con virreyes, gobernadores de provincias, particulares, tropas, autoridades eclesiásticas, encomiendas, tribunales, corregimientos, alcaidías, contadores, casas de la moneda, administradores y arrendadores de rentas reales (Guerrero Elecalde, 2012).

Si bien Felipe V no modificó las bases teóricas sobre las que se asentaba la organización política del reino -ya que se limitó a reorganizar su propia administración, la circulación de dinero en sus propias arcas y la elección de nuevos hombres-, al transformar las instituciones encargadas de la mediación entre el rey y el reino marginó sistemáticamente a los hombres tradicionalmente más poderosos, en un proceso en el que la negociación y el consenso jugaron un papel clave en la nueva constelación política.

Para ganar esta lucha era necesario, no sólo la reforma institucional abierta, sino también el cambio de los hombres que formaban esas instituciones: hombres nuevos, desprovistos de peso político propio, pero fieles al monarca. En la creación de este nuevo grupo se destacan, por una parte, los extranjeros, fundamentalmente los italianos o flamencos; por otra parte, el denominado colectivo 
norteño (Dedieu, 2001, pp. 394-396), integrado por hombres provenientes de Navarra, las provincias vascas, Cantabria, las montañas de Burgos y Asturias.

Se puede ver así la relación que se establece entre las políticas familiares, las trayectorias personales y las redes que se configuran en la dimensión del imperio (Imízcoz Beunza, 2002). Su llegada a los altos ámbitos de poder forma parte de la renovación de la política que intentaron Felipe $\mathrm{V}$ y los Borbones, por la cual la alta aristocracia castellana fue en parte desplazada de los cargos de gobierno en beneficio de estas nuevas familias elevadas por Felipe V. Los reinos americanos fueron arte y parte de este proceso, agentes activos del cambio, tal como lo fue la hasta entonces marginal provincia del Río de la Plata.

\section{Un territorio secundario en proceso de desmarginalización}

Desde principios del siglo XVIII, la Corona puso en juego una transferencia un cambio de estrategia con respecto al Río de la Plata, a partir del cual posibilitó y acompañó un proceso que en un principio mostraba la zona como un punto militar-estratégico, y que finalmente llegará a convertirse en el embrión del nuevo virreinato. Esta dinámica se hace particularmente evidente en toda la etapa de la Guerra de Sucesión y hasta la década de 1740. Este espacio fue también un campo donde brotaron las tensiones, como territorio de impacto de los ajustes que se producían en la búsqueda de un nuevo equilibrio europeo, y también como consecuencia de los objetivos políticos y militares que se planteó el nuevo rey. Al analizar las alternativas que experimentó la región en las diferentes gobernaciones, podrá apreciarse la militarización creciente de la misma, así como una asignación mayor de recursos tanto materiales como humanos por parte de la Corona hacia este espacio que tenía una calidad “marginal” o fronteriza del gran territorio del virreinato peruano (Tarragó, 2013)

Este sesgo militar de la política borbónica se hizo especialmente evidente en el Río de la Plata, ya que la instalación de la Colonia de Sacramento en 1680 implicaría para la Corona hacer un esfuerzo creciente por controlar esa cuña del poder portugués-inglés (Reitano y Possamai, 2015).

Las alternativas que se suceden en la gobernación de Buenos Aires nos revelan cómo este “embrión” comienza a gestarse, más evidentemente con el progresivo cambio de los elegidos para el cargo de gobernador y sus acompañantes, que viran hacia un perfil militar y más profesional (Tarrago, 2012; 2014)

Tras un largo proceso de selección, Su Majestad eligió directamente como gobernador del Río de la Plata al brigadier general Bruno Mauricio de Zavala, quien arribó a su gobernación portando con él

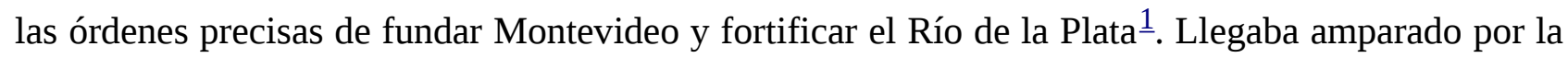
decisión de la Corona, que en 1701 había suspendido todas las designaciones "a futura” contra donativo gracioso. Despuntaba de esta manera, en el horizonte rioplatense, una presencia más controladora en el área, de la cual nació la gestión previa del juez pesquisidor Mutiloa (Andueza y Birocco, 2011)

El peso de la experiencia militar y de su lealtad declarada al régimen felipista primó sin atenuantes ante la gravedad de la situación en el Río de la Plata, con la Colonia en manos portuguesas y la amenaza inglesa permanente. Así lo señalan recurrentemente testimonios de la época: 
Y habiéndose dignado S. M. ceder nuevamente la Colonia a portugueses, en virtud de lo estipulado en los tratados de paz, le parece que no reuniendo el marqués de Salinas las experiencias militares y prudencia, de que. hoy necesita el manejo de aquel empleo, se sirva S. M. de elegir otro gobernador, en lugar de él, de los de mayor grado, conducta y experiencias militares, con el sueldo correspondiente, y que al marqués de Salinas se le dé recompensa equivalente, o que prontamente se le restituya el dinero que desembolsó por dicho gobierno, con la justa reflexión de lo mucho que pudiera haberle producido desde que le exhibió y ha dejado de percibir, en la buena fe de que le sería efectiva dicha merced. (...) y que se propusiesen a personas de graduación correspondiente y experiencias militares en los ejércitos de Europa ${ }^{2}$.[El resaltado me pertenece]

La preocupación se evidencia por

...la suma importancia de la plaza de Buenos Aires, que se halla sin gobernador dos años ha, revueltos entre sí los oficiales subalternos en quienes ha recaído el gobierno político y militar, y expuesta más que nunca a las asechanzas de portugueses e ingleses, lo que hace necesario el pronto pasaje del gobernador de Buenos Aires, con 300 hombres de infantería y caballería vestidos, armas y municiones y otros pertrechos de guerra que debe llevar para mayor resguardo y defensa de aquella importante plaza. Hace presente que al mariscal de campo Don José de Chaves le fue admitida la excusa para no aceptar dicho gobierno, y que todavía se hallan en manos de S. M. las consultas en que se proponen sujetos para aquel gobierno... ${ }^{3}$

El 28 de octubre volvió el Consejo de Indias a proponer candidatos, y esta vez el rey eligió de entre ellos al brigadier general Bruno Mauricio de Zavala, quien fue designado gobernador de Buenos Aires por real cédula de febrero de 1716. Primaba aquí el derecho-deber de defensa, para lo cual

...unos organismos engarzados de alta decisión adoptan medidas de dos tipos, de vertebración y cautela y adicionales, según sea su objetivo resolver preventivamente el núcleo organizativo de la acción militar, crear y mantener una situación de fortaleza, o incrementar fuerzas y recursos una vez suscitada la situación bélica (Pérez Prendes, 1986, p. 276).

Tenía por objetivos potenciar las fuerzas y asegurar las fortificaciones y comunicaciones. Si bien esos fines se alcanzaban con la generación de agrupaciones militares de personas aptas, se orientaron básicamente a conseguir guarniciones permanentes en los baluartes construidos con intención de estabilidad en los llamados presidios. Para ello se privilegió la construcción de puertos y fortificaciones, articulando la importación y adaptación de las técnicas, máquinas y artes.

Las autoridades de alta decisión controlaban la dirección y control de la fábrica, suministro, almacenamiento, conservación y distribución de artillería y armas, así como municiones y pólvora. A partir de estas potestades -y como Buenos Aires se encontraba por entonces en estado paupérrimo-, se previó la realización de levas para poder dotar al presidio de personal militar suficiente y adecuado.

Se pergeñan una batería de potestades, resucitadas y de nuevo cuño, recursos de poder que se vinculaban a la estimación que se tenía de estas tierras y de "la suma importancia de mantener 
aquella Plaza de Buenos Aires llave de todo el Reino del Perú de suerte que siempre se halle preservada de cualquiera invasión de enemigos” ${ }^{4}$. Así, entre otras disposiciones, interesa destacar la creación de un cargo de ayudante de caballería para el presidio $\underline{5}$ y la restitución del cargo de teniente del rey para asegurar la sucesión ante cualquier contingencia, para evitar situaciones como la “anarquía del año 14” (Birocco, 2012), provocada por la concurrencia de diferentes autoridades con presuntas jurisdicciones empatadas. No se hacía el nombramiento en el vacío, sino a partir de un diagnóstico claro de las necesidades emergentes del territorio, disponiendo

...y atendiendo a lo bien que me ha servido el Coronel Don Balthasar García de Rox de treinta y dos años a esta parte así en estos Reinos de España como en la América con diferentes puestos, hallándose actualmente gobernando en interim la referida Plaza de Buenos Aires y a que concurren en su persona las experiencias militares y demás circunstancias que se requieren para obtener el dicho empleo; He resuelto hacer merced al expresado Coronel Don Balthasar Garcia de Rox del referido empleo de Teniente de Rey o cabo subalterno del Gobernador y Capitán General de la dicha Ciudad de Buenos Aires para que en las ocasiones de falta, o, ausencia del Gobernador propietario de ella y sirva y ejerza el Gobierno político y Militar de aquella Plaza en la misma forma que pudiera y debiera hacerlo el Gobernador y Capitán General de ella... $\underline{6}$

Claramente se enfatiza la calidad doble del gobierno político y militar de la plaza, al explicitar que debe ostentar el mando “de una y otra jurisdicción”. En el mismo sentido, el rey avanza sobre el ámbito de la justicia mandando que el gobernador y sus sucesores elijan un letrado que los asesore ${ }^{7}$. Junto con ello se manifiesta una sarta de disposiciones que se ajustan a un trabajo previo de relevamiento e información sobre el estado de esa plaza y los recursos humanos y militares que es necesario enviar o reencauzar hacia ella. La reiterada orden a los oficiales reales de Potosí para que se regularice el envío del situado para la paga de la guarnición $\underline{8}$ se acompaña del crudo diagnóstico en el que la mayor parte de los soldados del fuerte se dedican administrar "tendejones" con los que subsisten malamente ${ }^{\underline{9}}$, haciendo que el desorden y los “vicios” se expandan más allá de lo esperable.

Inmerso en estas tramas y en conocimiento de la misión altamente compleja y difícil que se le encomendaba, el gobernador se entregó a estudiar la situación militar del Río de la Plata y concretó sus ideas en un informe que elevó a estudio de la Junta de Guerra de Indias. Era una suerte de plan de operaciones en el que se detallan aquellos asuntos sobre los que tenía que "tratar y resolver: el primero en orden a la Colonia del Sacramento; segundo, sobre ingleses avecindados en aquella plaza; tercero, acerca de los indios de las-misiones de la Compañía y el último sobre el juez pesquisidor que se halla en -aquella ciudad” $\underline{10}$.

Una densa investigación llegada de estas lejanas tierras se había utilizado para la planificación, especialmente la representación del capitán Blas Zapata, reformado del presidio de Buenos Aires, donde se expresaban las notables condiciones de abandono en que se encontraba aquél, en absoluta disparidad para enfrentar el conflicto con los portugueses $\underline{11}$. La voluntad regia de concretar esos objetivos se evidenciaba en las órdenes dadas 
...al virrey del Perú y Audiencia de Charcas, para que asistiesen con medios al gobernador de Buenos Aires; encargo para que el provincial de la Compañía de Jesús le enviase la gente que le pidiese en cualquiera necesidad ; en qué caso podría valerse el gobernador de Buenos Aires de todos los efectos de Real Hacienda, y de particulares... $\underline{12}$

También el gobernador interino Baltasar García Ros envía un informe utilizando la "vía reservada” en el que plantea su disconformidad con la entrega de Colonia de Sacramento $\underline{13}$. Los dichos elocuentes de aquél, en cuanto a los perjuicios que suponía para el área rioplatense sostener el enclave portugués, no bastaron para que Zavala debiera hacer cumplir lo prescripto en Utrecht, dando instrucciones para que

...a cuyo lado continuará en ínterin don Baltasar García Ros, con el empleo de Cabo subalterno de Buenos Aires, con quien deberá comunicar el propietario, y con acuerdo de ambos se haga lo que parezca más conveniente. $-Y$ habiendo venido $S$. M. en que conforme al artículo $6 .^{\circ}$ del tratado se ofrezca desde luego equivalente por la Colonia al Rey de Portugal, ordena se le proponga dentro del término del año y medio estipulado en el artículo $7 .^{\circ}$, que cumple el 2 de septiembre próximo, en la inteligencia de quedar en sus reales manos la consulta de 15 de julio para resolver sobre los otros puntos que incluye. $\underline{14}$

Previamente una junta de guerra ordenaba la fortificación de Buenos Aires y

Que se trabaje con el mayor empeño en estas obras. Que las armas de Cataluña llegadas a Cádiz y que han de ir a Buenos Aires, sean todas de un calibre: que dé la Junta y el Consejo, las órdenes necesarias para todo doy un extracto de ellas por la vía reservada, se pondrá en manos de su Majestad. $\underline{15}$

Zavala embarcó en el navío Nuestra Señora del Rosario el 11 de junio de 1717 junto con un grupo de militares veteranos, “que son hombres de calidad y sangre y que han servido muchos años y muy bien y con toda aprobación en el regimiento"16. El 10 de septiembre de ese año el secretario Grimaldo recibía una carta cifrada del gobernador en la que le informaba "que en 10 de julio de este año dio fondo en este surgidero y el 12 tomó posesión de su gobierno” $\underline{17}$. Para esa fecha también informaba de la entrega de la colonia que "el 4 de noviembre de 1716 se le dio al apoderado de Portugal, Don Manuel Gómez Barbosa, posesión de la Colonia del Sacramento por don Baltasar García Ros”. La gestión apela al sigilo y al extremo cuidado que ameritaba un orden de problemas que contaba con muchos enemigos internos. El 5 de abril de 1718 el mandatario remite una carta cifrada al marqués de Grimaldo aclarando que "excusa escribir a su señoría por la vía de Londres, y por mano de Don Miguel Fernández Duran dará cuenta al rey del estado de este presidio”ㅌ․

En un tiempo de iliquideces diversas de una Corona en guerra y transformación, la financiación del cambio tendrá impresas unas evidentes carencias sobre la disponibilidad de los recursos necesarios para llevar adelante tamaño plan de acción. Ante esa situación, la Monarquía conformará una plataforma sui generis, pero también bastante común en la tradición hispánica: de alguna forma sacará del territorio aquello que necesita para lograr el objetivo. Eso necesariamente llevó a la 
configuración de un sistema muy especial en el que diferentes agentes entran en ese juego y coadyuvan al cumplimiento, ya sea por servicio al rey o por beneficio propio, o ambas cuestiones intervinculadas. Es la forma, el camino alternativo pero posible que encuentra el rey al otorgar, por ejemplo, los contratos para los navíos de registro al puerto atlántico a cambio del traslado de tropas, del abastecimiento de armas, de la sustentación de los nuevos dispositivos militares. Será Andrés Martínez de Murguía el encargado de trasladar los trescientos efectivos que el rey había dispuesto pasasen a Buenos Aires $\underline{19}$.

A este gobernante lo esperaban trabajos y problemas conocidos, pero inmensamente difíciles de resolver por la simultaneidad de frentes, conflictividades bélicas y sociopolíticas altamente violentas. Así, como un augurio de lo que vendría y a poco de llegar, Buenos Aires sufría el azote de una peste que hacía estragos en los pobladores y en la guarnición $\underline{20}$.

No obstante las buenas intenciones y la decisión regia, la gobernación del vizcaíno desde 1717 a 1736 cubre un extenso y agitado periodo de la historia rioplatense. No se trataba de un territorio “cómodo”. El Río de la Plata era, por entonces, una especie de hormiguero ardido en el que pululaban con una afiebrada actividad barcos ingleses y de otras banderas:

Con este motivo hace presente a S. M. se sirva tomar la más pronta resolución en la consulta que desde el día 11 de junio está en sus manos, sobre la precisión de que en todo este año vayan los navíos a Buenos Aires y conduzcan al nuevo gobernador, gente, armas, municiones y pertrechos de guerra, para la defensa de aquella plaza, pues careciendo de un todo y lo que más es, de gobernador que la mande más ha de tres años, abanderizados los oficiales subalternos de ella, y expuesta más que nunca a lo que portugueses e ingleses quisieren ejecutar, los primeros por la Colonia del Sacramento y los segundos con motivo del establecimiento que se les permite en su cercanía durante los treinta años del asiento de negros ; deja a la consideración de su Majestad los perjuicios que podrán resultar de semejante abandono si prontamente no se acude por este medio a su reparo. $\underline{\underline{21}}$

Un largo informe del padre Bartolomé Jimenez $\underline{22}$ expone todos los males con los que el nuevo gobernador debería enfrentarse. El contrabando se realizaba con los marineros, oficiales y factores del asiento. Cada miembro de la tripulación de las naves negreras hacía su negocio particular, vendiendo los efectos con el propio navío o entregándolos a personajes de la ciudad, complicados con ellos. Es por ello que se recomienda "que hallándose ingleses domiciliados en Buenos Aires, necesita de una instrucción exacta y no ambigua del modo en que se debe portar con -ellos”.

El periodo está plagado de episodios constantes de fricciones esperables. No bastaba solo la fundación, sino la fortificación de todo el territorio uruguayo que rodeaba a la Colonia. En 1725, el virrey Castelfuerte concluye “con que convendrá no mudar de mano en el gobierno de Buenos Aires, así por la aprobación con que lo sirve Zabala como porque nadie conoce mejor que este oficial aquellos parajes y a los portugueses”르. Además de ello, los problemas en diferentes zonas fronterizas con poblaciones originarias insumieron gran parte de la energía de la gobernación (Avellaneda y Sidy, 2015) 


\section{A sangre y fuego por Felipe V: la experiencia paraguaya}

Paradójicamente, además de la faena montevideana-portuguesa, el otro frente de conflictos especialmente violento que debió afrontar Zavala se sitúa en Paraguay, provincia hasta entonces autónoma, fuera de la jurisdicción estricta que se le había encomendado en su designación. En ese lejano territorio, las tensiones de larga data entre paraguayos y jesuitas por el control de la mano de obra llevaron a una situación de enfrentamientos inusitados, denominados genéricamente como revueltas comuneras (Telesca, 2016). La progresiva disminución de la población de las reducciones sujetas a los encomenderos (Los Altos, Caazapá, Yutí, Ita, Yaguarón, Guarambaré, del Itapé y del Ipaná) había exacerbado los reclamos contra la orden jesuítica la que no solo controlaba las doctrinas de indios guaraníes, sino que contaba con privilegios reales en cuanto a la hacienda y a las condiciones de producción yerbatera. Los levantamientos se desarrollaron en dos etapas, dominadas por dos personajes procedentes de Nueva Granada: José de Antequera y Castro y Fernando de Monpó y Zayás.

El evento es extremadamente complejo en sus causalidades y agencias, pero una de sus variables más notables es el compromiso de la Orden Jesuítica en todo el devenir, tanto en el involucramiento de toda la cúpula de la Provincia de la Orden, como por el nivel de violencia contra ella, en la que no solo se implica el pesquisidor devenido en gobernador, sino gran parte del clero y del vecindario local (Avellaneda, 2014)

En esta instancia, el Virrey del Perú designa a Buenos Aires como el territorio desde el cual debe organizarse y partir la represión. Esto podría comprenderse desde un marco espacial e histórico: Paraguay y el Río de la Plata habían estado unidos en sus orígenes y Santa Fe y Corrientes nunca dejaron de ser un poco "paraguayas” (Barriera, 2013). Sin embargo, en la decisión de cargar sobre los hombros -ya recargados- de Zavala este inmenso foco de violencia se lee el nuevo lugar que ocupa la gobernación en el ámbito surperuano y atlántico $\underline{\underline{24}}$.

Zavala se encontraba por entonces altamente apretado por la fortificación de Montevideo, por lo que envió desde Buenos Aires a su segundo, Baltasar García Ros, con algunas fuerzas regulares, pero esencialmente apoyado por un ejército guaraní. Marchó entonces hacia Asunción. Mientras tanto Antequera puso preso a Reyes que estaba en Corrientes. Los asunceños hicieron frente a las tropas; García Ros salió derrotado en el cruce del Río Tebicuarí, y debió regresar a Buenos Aires. Al llegar a Asunción se dice que los “comuneros” gritaban “¡Viva el Rey, nuestro señor, don Felipe V ! ¡Vítor, señor Gobernador, que ya está vencido el enemigo! ¡Viva la provincia del Paraguay!”르. En el ínterin se produce un hecho extraordinario por todas las connotaciones políticas y jurídicas que conlleva: el Colegio de la Compañía en Asunción sufre el embate de los conjurados y sus integrantes son expulsados por autoridades civiles, sin respeto al fuero eclesiástico y en condiciones altamente violentas. El padre Herrán expone en la corte acerca de

...las grandes y continuas persecuciones que los religiosos de su provincia han padecido de los moradores de ella, sin dejar de ejecutar lo mismo con los indios de sus Doctrinas, habiendo llegado el odio a tal estado que han llevado a muchos indios presos y a dos Padres de la Compañía que los cuidaban, extrañando a todos los del Colegio de la Asunción... 26 
Llegado al virreinato, Armendáriz ordenó a Zavala intervenir. Esta es la forma que tiene el virrey de resolver de la manera más conveniente un problema que involucra tanto al buen gobierno de sus territorios como los intereses de sus aliados, los jesuitas. Lo hace con un hombre del mismo palo militar con arraigos personales por la vía familiar (Guerrero Elecalde, 2012; Tarragó, 2012 y 2014) con vínculos con los jesuitas y con conocimiento de esa última frontera con los portugueses que conformaba la gobernación del Paraguay. El gobernador no decepcionaría a su superior y aliado de la casa: logró entrar pacíficamente en Asunción el 29 de abril de 1725, poniendo al frente de la gobernación al teniente de gobernador de Santa Fe, Martín de Barúa 27 , y sacando de prisión a Reyes. Antequera escapó, pero en Córdoba fue capturado y enviado a Lima, donde fue condenado a muerte y ejecutado.

Por ese tiempo llegó a Asunción un oscuro personaje, Mompó y Zayás, quien había estado preso en Lima. Allí había obtenido información de los amigos de Antequera. Logró fugarse y llegó a la ciudad paraguaya, donde se vinculó con el alcalde de primer voto, Fernando Curtido, parcial de Antequera, quien a su vez lo recomendó a Barúa. Este particular actor enseñaba que el poder del pueblo, o sea el “común”, era mayor que el del rey, que en sus manos estaba admitir la ley o el gobernador que gustasen, porque aunque se lo diese el príncipe, si el común no quería podía justamente resistirse y dejar de obedecer. Apoyándose en conceptos de honda raigambre tradicional hábilmente expuestos, se tejía una tesis extremista propicia a la anarquía local. Mompó y Zayás podía leer a los asunceños algunos párrafos del P. Juan de Mariana sobre el poder real y sus limitaciones, y -exagerando un poco- afirmar la ortodoxia de su posición, de manera que su prédica encontraría rápido eco, porque se daban en el Paraguay condiciones sociales para ello $\underline{28}$.

A fines de 1730 se supo en Asunción que había sido nombrado gobernador de la provincia Ignacio de Soroeta. La sola noticia de haber sido nombrado por el virrey alarmó a los antequeristas, a los que se plegó Mompó. El 28 de diciembre, algunos centenares de “comuneros” entraron en Asunción para pedir a Martín de Barúa que no entregara el mando a Soroeta. Barúa no se atrevió a tanto; se presentó ante el cabildo, renunció a la gobernación y se dispuso a abandonarla, dejándola acéfala frente a un posible caos. A principios de 1731 fueron designados los alcaldes bajo el influjo de los comuneros, recayendo los cargos en José Luis Barreiro y Pedro Bogarin, quedando Asunción en manos de dos gobiernos, el del Cabildo y el revolucionario, dirigido éste por Mompó y Zayás.

Hasta agosto de 1731 los comuneros se alzaron otra vez, obligando a Barreiro a refugiarse en el convento de La Merced para salvar la vida. Pudo huir, saliendo del Paraguay, que quedó en manos de los revolucionarios. Por ese entonces llegaron noticias de las ejecuciones de Antequera y Mena, lo que provocó intensa conmoción. Indignados los comuneros y pese a los esfuerzos del obispo Palos, que había regresado a su sede, se decretó la expulsión de los jesuitas, medida que se hizo efectiva con graves ultrajes para tales religiosos. Al año siguiente un nuevo gobernador -Martín Agustín de Ruiloba Calderón- fue asesinado y su cadáver ultrajado. Fray Arregui, que por ese tiempo era obispo de Buenos Aires, se involucró en las rebeliones. $\underline{29}$

Una vez más el virrey del Perú ordenó a Zavala pasar a Paraguay, a ejecutar drásticas y definitvas medidas. La orden la recibió junto con los despachos que lo designaban para ocupar la gobernación y presidencia de Chile $\underline{30}$. En noviembre de 1734 partió hacia el norte con apenas una escolta de 
cuarenta infantes y cinco dragones, pues la tensa situación de Colonia de Sacramento no aconsejaba debilitar la guarnición de Buenos Aires. Llegó a Corrientes, en donde gran parte de la ciudad se había plegado a la rebelión. El 25 de enero de 1735 instaló su campo a cuatro leguas del Tebicuarí, al frente de un ejército que contaba con seis mil indios de las misiones. La campaña militar, en la que se distinguió Martín José de Echauri, fue rápida. Los comuneros fueron derrotados y muchos capturados prisioneros, entre otros los cabecillas. Al finalizar su labor en Asunción, Zavala dejó al frente de la gobernación del Paraguay a su paisano y hombre de confianza, Martín José de Echauri, hecho lo cual emprendió viaje de regreso a Buenos Aires.

\section{Un final poco feliz}

Zavala murió en el camino de vuelta... De alguna manera, había fallecido de esas revueltas en las que paradójicamente no habría tenido incumbencia alguna si su gobierno se hubiera ajustado a la jurisdicción. Ese foco insano e irresoluble le consumió gran parte de sus energías. ¿Por qué tenía que ocuparse un gobernador de “otra gobernación”? Un tándem letal que hilvanaba las agencias del virrey, la Corte y los jesuitas agregaron una presión descomunal sobre las capacidades militares y de gobierno de Zavala, que debió permanecer cinco años (hasta su muerte) más, aunque ya hubiese sido nombrado para un cargo de mayor jerarquía como el de la Capitanía General de Chile.

En esa escalada de decisiones se lee el poder del rey a través de su virrey, pero también la agencia de los jesuitas que han dado mucho para ello, pero que reclaman por el pago donoso de todo ese aporte al servicio real. Ellos son la clave en las disputas de poder y legitimidad en el Paraguay donde se les acusa de que "apoderados de los gobernadores de Buenos Aires y Tucumán y sus Justicias a más de dos años, tienen puesto cerco a esta provincia, prendiendo a cuantos salen de él”.

La orden constituyó una fuente fundamental para información de la Corona sobre las necesidades, problemas, etc. que presentaba el territorio (Avellaneda, 2014). Los diversos, memoriales, cartas, papeles, informes de diferentes miembros ignacianos no solo incluían consideraciones acerca de las necesidades de la Congregación en sí, sino que eran una fuente inagotable de datos concretos y estratégicos. Así, el "Papel del Padre Bartolomé Jiménes de la Compañía de Jesús sobre excesos de los españoles contra los pobres indios del Paraguay. Tucumán y Buenos Aires v otras reflexiones dignas de consideración y de remedio” del 14 de febrero de 1717” resulta un cuadro altamente descriptivo de las condiciones del área rioplatense-paraguaya. La indefensión de las costas del Río de la Plata frente a los avances portugueses, la necesidad de control y fortificación de ambas márgenes del Río para proteger todo el territorio (incluso el Perú), la premura de regularizar el movimiento del puerto, las ventajas de Buenos Aires como punto de comunicación más efectiva con la Península, las desventajas de la venta de oficios y la urgencia de rescatar y colocar gobernadores idóneos:

La práctica antigua de las Indias fue siempre proveer los gobiernos de aquellas provincias en militares, por cuanto todas las gobernaciones del Paraguay, Buenos Aires y Tucumán están como bloqueadas de infieles enemigos. Es necesario se prosiga la misma práctica, pues los gobernadores imperitos en el arte militar nunca han sabido atender al castigo de los bárbaros...[El resaltado me pertenece] 
...además de defender el sistema de producción-circulación de la yerba mate en las reducciones bajo su cuidado, los problemas con pueblos originarios en áreas de frontera, la sugerencia de introducir africanos esclavizados (etíopes) para cubrir las necesidades de trabajo más duros.

Un completo plan de acción en el que resulta fácil comprender que la agenda de la Corona se mimetiza en alto grado con la agenda jesuítica, sin cuya agencia no podía concretarse el cambio. En su estudio clásico, Magnus Mörner asocia estas acciones con los intereses económicos de los jesuitas en el área en torno a la producción de yerba mate para las cuales obtuvieron beneficios excepcionales (Garavaglia, 1982). También añade que se vincularon a la trata negrera del asiento inglés, dentro de la cual involucra también a Baltasar García Ros y al mismo Zavala. $\underline{32}$

Tanto los sucesos de las rebeliones comuneras como otros, vinculados al momento de fundación y fortificación de la línea Montevideo-Maldonado-Colonia, son especialmente didácticos para comprender el proceso desde sus entrañas mismas. El asunto envuelve problemas conceptualmente densos que involucran también a los límites jurisdiccionales entre gobernación temporal y gobernación espiritual.

Como se dijo, cuando Zavala navegaba por el Paraná falleció de un ataque cerebral o apoplejía, una patología esperable luego de casi veinte años de tensiones y convulsiones en los territorios que se le había ordenado gobernar. Así, esa muerte deja un sabor de “inconclusión”, de incertidumbre y final amargo de un mandato que parecía contar con toda la fuerza de la nueva dinastía. Pero el servicio al rey era un gran monstruo que se deglutía a quien entraba en sus fauces.

Para la inconmensurable cantidad de problemas que debió resolver, y sobre los que inexorablemente tuvo que tomar drásticas y contundentes decisiones, se requería de todos los recursos, aquellos que refrendaran y no dejaran dudas de que el brazo férreo de Felipe V había llegado al Río de la Plata. Pero esos recursos resultaron escasos y el primer gobernador borbónico debió gobernar con ayuda de su red de militares vizcaínos que le aseguraran fidelidad y presencia, con el apoyo de los ejércitos indígenas comandados por los jesuitas, con los agentes del asiento inglés, con los registreros, con la voluntad y exigencias del virrey del Perú para que le enviara el situado a tiempo. También con la asistencia rápida de tramas políticas, económicas y parentales, que lo conectaban con instancias de poder superiores y capitales simbólicos y materiales a los que necesariamente debió echar mano para tratar de controlar ese mundo diverso y policéntrico difícil -cuando no imposible- de rescatar para un orden aún lejano en la primera mitad del siglo XVIII.

En la observación de esa complicada gestión se cruzan inexorablemente las propuestas teóricas y metodológicas de este artículo. Tanto en la vitalidad que la Monarquía compuesta -en tanto cultura política- tiene en pleno período borbónico, como la presencia inexorable de agencias y redes que configuran y le dan sentido tanto a las formas de ejercicio del poder como a la ordenación misma de esa sociedad que deben encauzarse por decisión real, al sometimiento de rémoras territoriales de viejo cuño, como a las concretas amenazas que el nuevo concierto internacional planteaba para esa región. 


\section{Notas}

1 AGN, Reales Ordenes, Libro 2, 24-20-10, Reales Ordenes, Libro 1, 24-10-9, Reales Ordenes, Libro 1 24-10-10, Comunicaciones y Resoluciones Reales, Libro 1, Años 1716-1770.

$\underline{2}$ AGI, 75-6-36 (signatura Antigua) El Consejo de Indias a su majestad, 11 de agosto de 1715 Pastells, Pablo R. P., 1946, p. 8.

$\underline{3}$ AGI, 75-6-16, signatura antigua, Junta de Indias, 14 de noviembre de 1715. Pastells, Pablo R. P., 1946, p. 35.

4 AGI, Buenos Aires, 4, L. 14, f. Folio 94, Brigadier Dn Bruno Maurizio de Zavala, Cav.o del Horden de Calatrava, a q.n he nombrado pr mi Gov.or y Cao.n gral de la Ciudad de la Trinidad y Puerto de Buenos Aires en las Provincias del Rio de la Plata en quince de marzo de este presente año tuve por bien de expedir una Cedula en q. va inserta otra de veinte de Nov.re de mil setez.tos y catorze cuyo thenor de ella es como le sigue. RC, 12 de setiembre de 1716 .

$\underline{5}$ AGI, Buenos Aires, 4, L. 14, f. Folio 57, RC 5 de mayo de 1716.

6 AGI, Buenos Aires, 4, L. 14, f. Folio 70-72 V, Al Virrey del Peru pa que haga que los Ofiz.s Rs de Potossi Remitan a BsAys en todas las ocass.nes de envio del situado de 3000 ps mas en cada un año pa satisfacer el sueldo qe se ha señalado al Then.te del Rey, o cavo subalterno qe V.M. sea serv.do dar pa aquella Plaza. RC, 28 de setiembre de 1716.

Z AGI, Buenos Aires, 4, L.14, f. 83.

8 AGI, Buenos Aires, 4, L.14, f. 94.

9 AGI, Buenos Aires, 4, L.13, fs. 39-40.

10 AGI, 76-2-16, signatura antigua, en Pastells, Pablo R. P., 1946, pp. 57-58.

11 AGI, 7-6-24, signatura antigua, en Pastells, Pablo R. P., 1946, pp. 55-57.

12 AGI, 75-6-10, signatura antigua, en Pastells, Pablo R. P, 1946, p. 60.

13 AGI, 75-6-16, signatura antigua, Decreto de su Majestad al Real Consejo de Indias, 24 de julio de 1716, Pastells, Pablo R. P, 1946, pp.70-75.

14 AGI, 75-6-16, signatura antigua, El Consejo extraordinario de Indias a S. M., 6 de agosto de 1716 en Pastells, Pablo R. P., 1946, pp. 77-78.

15 AGI, 75-6-16, signatura antigua, S. M. a la Junta de Guerra, Aranjuez, 7 de mayo de 1716. Al Conde de Frigiliana Pastells, Pablo R. P., 1946, p. 54.

16 AGS, Sec. Guerra, 2242, correspondencia de Miguel Fernández de Durán al Marqués de Aytona, noviembre de 1716.

17 AGI, 76-2-24, signatura antigua, en Pastells, Pablo R. P., 1946, p. 160. 
18 AGI, 76-2-24, signatura antigua, Pastells, Pablo R. P., SJ Historia de la Compañía...,cit., t. 6 , p. 167.

19 AGI, Buenos Aires 4, L.14, f.139, 25 de abril de 1716.

20 AGI, 75-6-18 en Pastells, Pablo R. P, 1946, p. 391.

21 AGI, 75-6-16, signatura antigua, El Consejo de Indias a Su Majestad, 15 de julio de 1716, en Pastells, Pablo R. P., 1946, p. 62.

22 Papel del Padre Bartolomé Jimenes de la Compañía de Jesús sobre excesos de los españoles contra los pobres indios del Paraguay. Tucumán y Buenos Aires v otras reflexiones dignas de consideración y de remedio. Al señor don Francisco de Castejón, secretario del Consejo Real de Indias, y enviados por éste en 14 de febrero de 1717. —Dice que por haber residido cuarenta y dos años en dichas provincias y obtenido las noticias verdaderas, unas de vista y otras de oídas y de buenos originales pertenecientes al estado de las mismas, hallando ser muy propio de su incumbencia representar en escrito algunos puntos concernientes a la seguridad, conservación y feliz progreso de tales provincias, sin pretender más que el servicio de Dios y de Su Majestad para que con sus ministros ejecute lo que fuere del mayor servicio de Dios y utilidad común* de dichas provincias. AGI, 76-5-18, signatura antigua, en Pastells, Pablo R. P, 1946, pp. 1136-145.

$\underline{23}$ AGI, 76-2-25, signatura antigua, Carta del Marques de Castelfuerte, Virrey del Perú, a Su Majestad, 17 de noviembre de 1724, en Pastells, Pablo R. P., 1946, p. 372.

24 Carta del Virrey, Marques de Castelfuerte, a Su Majestad.-Da cuenta dilatadamente de las inquietudes causadas en la provincia del Paraguay por don José de Antequera y lo ejecutado por éste en contravención de las órdenes que se le expidieron por el Superior Gobierno y providencias dadas por el Virrey a fin de que pasase a dicha provincia en persona con gente del Gobernador de Buenos Aires para su pacificación, y remite copia de las órdenes que le ha dado, concluyendo "con haber tenido noticia que dicho Gobernador de Buenos Aires salió de aquella ciudad para dicha provincia el día 16 de diciembre del año próximo pasado y que quedaba esperando su resulta con el cuidado correspondiente a esta empresa.-Lima y marzo 25 de 1725. AGI, 76-3-50, signatura antigua, en Pastells, Pablo R. P., 1946, pp. 392-4.

$\underline{25}$ AGI, 76-3-49, signatura antigua, Traslado concorde con el testimonio de su contexto de los autos remitidos por el Cabildo, Justicia y Regimiento de la Asunción del Paraguay sobre lo sucedido en la entrada de don Baltasar García Ros, hecho de oficio por el Escribano de Cámara de la Real Audiencia de La Plata, don Mateo de Suero y Gonsáles, de mandato verbal de los señores Presidente y Oidores de ella, siendo testigos Matías de Bedoya Campuzano y Simón Narciso de Valencuela, 3 de diciembre de 1725, Pastells Pablo R. P., 1946, p. 463.

26 AGI, 76-5-9, signatura antigua, Memorial de Jerónimo Herrón de la Compañía de Jesús, Procurador general por la provincia del Paraguay, a Su Majestad, 21 de enero de 1726, en Pastells, Pablo R. P., 1946, pp. 473-79.

27 AGI, 76-3-1, signatura antigua, Auto proveído en La Asunción en 25 de junio de 1725, por don 
Bruno de Zabala.—Certifica su comisión, viaje y llegada a dicha ciudad ; su pacificación ; el nombramiento interino de Gobernador a favor de don Martin de Barúa ; la aceptación del mismo por el Cabildo, y la retirada de don Bruno a Buenos Aires. En Pastells, Pablo R. P., 1946, p. 421.

$\underline{28}$ AGI, Charcas, 323, Informe del señor Fiscal en vista de diferentes cartas del Paraguay, sobre no haber querido admitir la ciudad de la Asunción al gobernador interino don Ignacio de Soroeta por sucesor de Barúa, que nombró el Virrey.-Reconoce la gravedad de este expediente, y aunque hasta ahora no consta que los Comunes y militares tumultuados hayan ejecutado más violencias que las de haber resistido admitir al nuevo Gobernador, se puede recelar lo practiquen así, en cualquiera providencia contraria a sus intentos, lo que se habrá reflexionado asi por el Virrey como por la Audiencia de los Charcas, a quienes dio cuenta con autos el Cabildo secular del Paraguay, y es muy verosímil que en vista de ellos hayan dado prontas providencias para sosegar la turbación y castigar los causantes del motín; por cuya razón no parece tiene estado este expediente para que por el Consejo se pueda tomar providencia alguna, no sólo porque cualquiera que se diese llegaría fuera de tiempo, como porque el Virrey y Audiencia la tendrían dada, y es muy regular que en los galeones avisen con auto de lo que hubieren ejecutado. Y así considera el Fiscal se podrán esperar éstos para que en su inteligencia y del informe del Virrey y Audiencia se resuelva lo más conveniente, y en ínterin se dé noticia de lo referido a Su Majestad y del expresado fundamento que tiene el Consejo para no haber tomado por ahora providencia en ello. Y por lo que mira al Abogado don Fernando de Zayas que, según refiere el Gobernador de Buenos Aires, se considera el principal motor de esta sublevación, si pareciere al Consejo, se podrá expedir orden particular al Virrey se proceda contra él por todos los medios en derecho prevenidos. Y en cuanto en lo que añade el Gobernador Barúa de los recelos que tiene del Obispo y el testimonio que remite de lo que ha ejecutado en este caso, parece asimismo que por no haber llegado informe alguno de este Prelado, no hay que hacer, y que se podrá tener presente por si llegare, para que en su vista se pueda resolver lo correspondiente a lo que resultare de los autos que se remitieren y lo que ha incluido este Gobernador.-Madrid, 28 de octubre de 1731. En astells, Pablo R. P., Mateos, F., 1948, Tomo VII, pp. 2-4.

29 AGI, Charcas, 323, Testimonio de los documentos presentados (d Marqués de Castelfuerte con motivo de haber repelido los sublevados de la provincia del Paraguay a don Ignacio de Soroeta de los cargos de Gobernador y Capitán general de esta provincia, 30 de noviembre de 1731. En Pastells, Pablo R. P., Mateos, F. SJ 1948 , pp. 20-29.

30 AGI, 30 Charcas, 183. Título de Gobernador y Capitán General de las provincias del Río de la Plata a don Miguel de Salcedo, en virtud de Real Decreto de 25 de noviembre de este año, dado con motivo de haber promovido a don Bruno Mauricio de Zabala al gobierno y Capitanía General de Chile y Presidencia de la Audiencia que reside en la ciudad de Santiago. — Sevilla, 30 de diciembre de 1731. en Pastells, Pablo R.P., Mateos, F. SJ, 1948 , p. 30.

31 AGI, 76-3-49, signatura antigua, Traslado concorde con el testimonio de su contexto de los autos remitidos por el Cabildo, Justicia y Regimiento de la Asunción del Paraguay sobre lo sucedido en la entrada de don Baltasar García Ros, hecho de oficio por el Escribano de Cámara de la Real Audiencia de La Plata, don Mateo de Suero y Gonsáles, de mandato verbal de los señores Presidente y Oidores de ella, siendo testigos Matías de Bedoya Campuzano y Simón Narciso de 
Valencuela, 3 de diciembre de 1725, en Pastells, Pablo R. P., Mateos, F. 1948, p. 447.

$\underline{32}$ "No obstante la diferencia de confesión, no vacilaron en vincularse económicamente con los ingleses del Asiento. Al suspenderse éste por vez primera en 1719, a causa de la guerra de Alberoni, el procurador de las Misiones en Buenos Aires, padre Diego Garvia presentó un crédito de 16.000 pesos contra los bienes confiscados a los ingleses. Es posible, sin embargo, que en realidad hiciese de testaferro del gobernador Zabala, como se insinúa en un documento contemporáneo. En todo caso, el contacto se reanudó después de la primera restitución del Asiento en 1722. Dos años más tarde, el procurador de las Misiones (ahora el Padre Jerónimo Herrán, obtuvo del Asiento una letra de cambio sobre Londres por valor de 12.000 pesos; casi todo el importe fue abonado por don Baltasar García Ros, jefe de la guarnición. Después de la segunda represalia contra el Asiento en 1727, observamos otra vez la conexión entre jesuitas y esclavistas ingleses, en que estaban interesados también altos oficiales españoles, como García Ros”. Mörner, 2008 (1953), p. 159.

\section{Bibliografía}

Adrien, K. (2012). The Bourbon Reforms. Oxford bibliographies.com.

Andújar Castillo, F. (2004). El sonido del dinero. Monarquía, ejército y venalidad en la España del siglo XVIII. Madrid: Marcial Pons Historia.

Arrieta Alberdi, J. (2009-2010). Entre monarquía compuesta y estado de las autonomías. Rasgos básicos de la experiencia histórica española en la formación de una estructura política plural. IVS FVGIT Revista de Estudios Histórico-Jurídicos de la Corona de Aragón, vol. 16, 9-72.

Avellaneda, M. (2014). Guaraníes, criollos y jesuitas. Luchas de poder en las Revoluciones Comuneras del Paraguay. Siglos XVII y XVIII. Asunción: Editorial Tiempo de Historia.

Avellaneda, M., y Sidy, B. (2015). Políticas, levantamientos y relaciones de poder en las fronteras externas e internas en los albores del período borbónico. la actuación de Bruno Mauricio de Zabala, gobernador del Río de la Plata (1717-1735). Memoria Americana, 23(1), 69-98.

Birocco, C. (2011). La pesquisa de Mutiloa en Buenos Aires. Conformación de facciones y lucha de poder en el cabildo porteño (1700-1715). En P. Polimene (comp.), Autoridades y prácticas judiciales en el Antiguo Régimen. Problemas jurisdiccionales en el Río de la Plata, Córdoba y Tucumán, Cuyo y Chile (pp.33-56). Rosario: Prohistoria Ediciones.

Birocco, C. (2012). En torno a la anarquía del 1714. La conflictividad política en Buenos Aires a comienzo del siglo XVIII. Anuario del Instituto de Historia Argentina, 71-98.

Birocco, C. (2015). La élite de poder en Buenos Aires colonial: Cabildo y Cabildantes entres los Habsburgos y los Borbones (1690)-1726 (Tesis de doctorado), Universidad Nacional de La Plata, La Plata, Argentina.

Dedieu, J. (2001). Dinastía y élites de poder en el reinado de Felipe V. En P. Fernández Albaladejo (ed.), Los Borbones. Dinastía y memoria de la nación en la España del Siglo XVIII. Madrid: Marcial Pons Historia/Casa Velázquez. 
Feros, A. (1998). Clientelismos y poder monárquico en la España de los siglos XVI y XVII, A.A.V.V La monarquía española: grupos locales ante la corte de Madrid. Relaciones-Estudios de Historia y Sociedad, Relaciones, 19(73), 15-49.

Garavaglia, J. C. (1982). Mercado interno y Economía Colonial. México: Grijalbo.

Guerrero Elecalde, R. (2012). Las elites vascas y navarras en el gobierno de la Monarquía borbónica: Redes sociales, carreras y hegemonía en el siglo XVIII (1700-1746). Bilbao: Universidad del País Vasco.

Imízcoz Beunza, J. M. (dir.) (2002). Redes familiares y patronazgo. Aproximación al entramado social del País Vasco en el Antiguo Régimen (Siglos XV-XIX). Vitoria: UPV.

Jumar, F. (2000). Le commerce Atlantique au Rio de la Plata, 1680-1778 (Tesis de doctorado), École des Hautes Études en Sciences Sociales, París, Francia.

Kossok, M. (1972). El Virreinato del Río de la Plata. Buenos Aires: La Pléyade.

Levene, R. (director general) (1961). Historia de la nación argentina (desde los orígenes hasta la organización definitiva en 1862). Buenos Aires: Academia nacional de la Historia/el ateneo.

Lucena Guiraldo, M. (1996). El reformismo borbónico y los indígenas fronterizos americanos. En A. Guimerá (ed.), El reformismo borbónico. Madrid: Alianza Universidad.

Pearce, A. (2014). The Origins of Bourbon Reform in Spanish South America, 1700-1763. New York: Palgrave.

Outram, D. (2011). La Ilustración. México: Siglo XXI.

Moriconi, M. (2014). Configuraciones eclesiásticas del territorio santafesino en el siglo XVIII (Tesis doctoral), Universidad Nacional de Rosario, Rosario, Argentina.

Mörner, M. (2008-1953). Actividades políticas y económicas de los jesuitas en el Río de la Plata. Buenos Aires: Centro Editor de Cultura.

Lynch , J. (1958). Spanish Colonial Administration, 1782-1810. The Intendant System in the Viceroyalty of the Río de la Plata. Londres: University of London.

Pastells, P. R. P. (1946). SJ Historia de la Compañía de Jesús en la Provincia del Paraguay (Argentina, Uruguay, Perú, Bolivia y Brasil) según los documentos del Archivo General de Indias, Madrid, Librería General de Victoriano Suárez, Tomo VI.

Pastells, P. R. P., Mateos, F. (1948). SJ Historia de la Compañía de Jesús en la Provincia del Paraguay (Argentina, Uruguay, Perú, Bolivia y Brasil) según los documentos del Archivo General de Indias, Madrid, Consejo de Investigaciones científica-Instituto Santo Toribio de Mogrovejo, Tomo VII.

Perez Prendes y Muñoz de Arracó, J. (1989). La Monarquía Indiana y el Estado de Derecho. Valencia: Asociación Francisco López de Gómara.

Ravignani, E. (1983). El virreinato del Río de la Plata. Su formación histórica e institucional, Buenos Aires: Academia Nacional de la Historia. 
Reitano, E., y Posamai, P. (coord..) (2015). Hombres, poder y conflicto. Estudios sobre la frontera colonial sudamericana y su crisis. La Plata: Universidad Nacional de La Plata.

Rosanvallon, P. (2015). El buen gobierno. Buenos Aires: Manantial.

Ruiz Torres, P. (2008). Historia de España. Reformismo e Ilustración, Volumen V. Barcelona: Crítica - Marcial Pons.

Sánchez Blanco, F. (2002). El absolutismo y las Luces en el reinado de Carlos III. Madrid: Marcial Pons Historia.

Sánchez Santiró, E. (2016). Las reformas borbónicas como ctagoría de análisis en la historiografía institucional, económica y fiscal sobre Nueva España: orígenes, implantación y expansión. Historia Caribe, 11(29), 19-51.

Tarragó, G. (2012). Espacio, recursos y territorio: la Gobernación del Río de la Plata durante el reinado de Felipe V. En O. Mazín, y J. Ruiz Ibáñez (Editores) Las Indias Occidentales. Procesos de incorporación territorial a las Monarquías Ibéricas (pp. 281-327). México: El Colegio de México/Red Columnaria.

Tarragó, G. (2014). Espacios en tensión, territorios en construcción: Santa Fe y Buenos Aires durante la primera etapa borbónica (1700-1745). En D. Barriera y R. Fradkin (coord), Gobierno, justicias y milicias: la frontera entre Buenos Aires y Santa Fe 1720-1830, 1a ed (pp. 41-70). La Plata: Universidad Nacional de La Plata.

Trujillo, O. (2013). Consenso, negociación y conflicto en la Monarquía Hispánica: la élite de Buenos Aires en el Siglo XVII. Luján: Universidad Nacional de Luján.

Tellesca, I. (2016). De las revueltas comuneras a las ligas agrarias. Un balance historiográfico (y documental) sobre el rol del cura rural secular en Paraguay. Anuario IEHS: Instituto de Estudios histórico sociales, 31(1),135-147. 